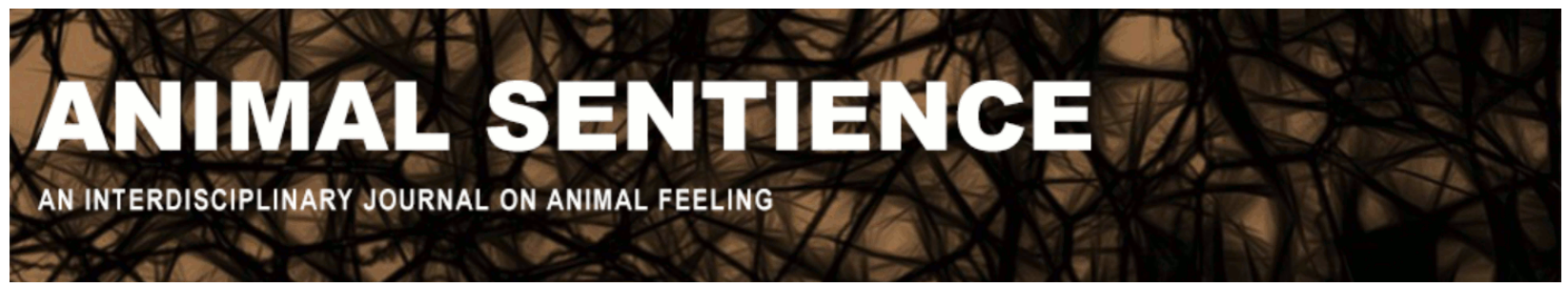

Broude, Gwen J. (2016) Still wondering how flesh can feel. Animal Sentience 11(13)

DOI: $10.51291 / 2377-7478.1185$

Date of submission: 2016-12-22

Date of acceptance: 2016-12-26

(c)

This article has appeared in the journal Animal

Sentience, a peer-reviewed journal on animal

cognition and feeling. It has been made open access,

free for all, by WellBeing International and deposited

in the WBI Studies Repository. For more information,

please contact

wbisr-info@wellbeingintl.org.

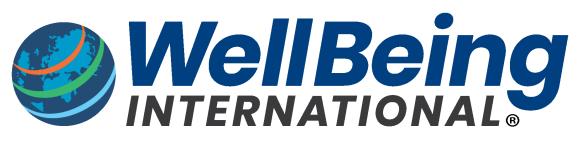

SOLUTIONS FOR PEOPLE, ANIMALS AND ENVIRONMENT 


\title{
Still wondering how flesh can feel
}

Commentary on Reber on Origins of Mind

\author{
Gwen J. Broude \\ Cognitive Science, Vassar College
}

\begin{abstract}
Reber believes he has simplified Chalmers's "hard problem" of consciousness by arguing that subjectivity is an inherent feature of biological forms. His argument rests on the related notions of continuity of mind and gradual accretion of capacities across evolutionary time. These notions need to be defended, not just asserted. Because Reber minimizes the differences in mental faculties among species across evolutionary time, it becomes easier to assert, and perhaps believe, that sentience is already present in early biological forms. The more explicit we are about the differences among these mental faculties and the differences across species, the less persuasive is Reber's claim of the mental unity of species. The further claim that mental faculties develop gradually across evolutionary time is not empirically justified. How sentience can be "inherent" in biological forms is still not an "easy problem."
\end{abstract}

Keywords: Chalmers, hard problem, mind, consciousness, sentience, epigenesis

Gwen J. Broude is Professor of Cognitive Science at Vassar College. Her research interests include the application of crosscultural and evolutionary theory to human mind and behavior. She also has an interest in phenomenological approaches to mind.

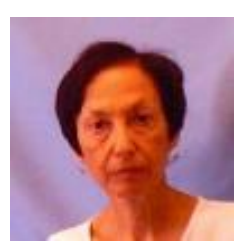
https://cogsci.vassar.edu/bios/broude.html

Reber (2016) proposes a resolution to or at least a simplification of the "hard problem" of consciousness (Chalmers 1996). Reber's solution, which depends on what he calls "a simple, perhaps radical axiom," is that "subjectivity is an inherent feature of particular kinds of organic form" and is "present in the most primitive of species." Different manifestations of subjectivity across species lie on a continuum and thus are not qualitatively different. The claim rests on the assumption that evolutionary changes across species are continuous so that "what gets 'added' isn't ontologically novel; it's a gradual accretion of functions that are layered over and interlock with pre-existing ones." The "hard problem" then becomes a simpler problem because we no longer need to worry about when consciousness emerges. It was there already in the most primitive of species.

I will focus here on three questions: Is evolution just or always a matter of gradual accretions of function? Because if it is not, then Reber's case is diluted. Should we assume that all mental states and capacities in all or almost all species are basically just variations on a theme? Because if they are not, then something new must have been added. And - has Reber transformed the "hard problem" into a simpler problem? 
The assumption of gradual accretion of functions across evolutionary time is what allows Reber to state that all minds are just a variation on the theme of mind. Without gradual accretion and quantitative change with nothing novel added, there is nothing to support his contention that not only are sentience, mind, consciousness, and the like inherent to biological forms but they are also basically the same in all biological forms, or close enough so there is no emergence problem to solve. But the idea of gradual accretion of functions implies that a change in some entity, event, or process across time is quantitative and not qualitative. Reber's argument assumes three kinds of gradual change, all causally linked. A gradual alteration in the genome underlies a gradual change in the physical structure of the organism which underlies a gradual change in the mind of the organism. The question becomes whether a qualitative change in mind can be achieved without an analogous qualitative change in the genome or the underlying physical structure. (Note that this leaves aside the question of whether genomes or physical structures only change gradually in the first place.)

There is not necessarily an isomorphic relationship between a change in an underlying mechanism, whether genome or physical structure, and the change the mechanism produces. A gradual change in the genome does not guarantee a gradual change in, say, the brain. Nor does a gradual change in the brain necessarily lead to a gradual change in mind or behavior. Even if the genome or the brain changes gradually, mind and behavior mind may change qualitatively rather than gradually.

Is it possible to achieve qualitative changes in mental function in the absence of qualitative change in the underlying mechanism? There are connectionist models of brain function in which connection weights representing synaptic connections change gradually during a training routine while the system's behavior changes abruptly from one trial to the next (Elman et al. 1997). If the model were a human being, we might say it had a flash of insight. So, there is no necessary mechanism-outcome isomorphism. It is also possible for a genome to not change at all yet produce surprisingly different outcomes in different environments or contexts, a phenomenon whose consequences we witness every day as organisms develop. The phenomenon of epigenesis (Oyama 2007; Gottlieb 2007) also challenges the assumption that the genome is the only thing that shapes the mind. If it is indeed possible for features of mind to be ontologically novel across evolutionary time, even with only a gradual change in genome, or no change at all, then Reber needs to show why sentience is not one of those ontologically novel features.

Reber also minimizes the differences in mental faculties over evolutionary time: "Reactivity, consciousness, intentionality, memorial representation, creativity and all the rest are the manifestations of particular kinds of organic stuff. When you get simple collections of this stuff, you get primitive, subjective reactivity; when you get complexly organized and structured stuff, you get complex mentation and representation, self-reflection and modulation, insight and ecstasy, despair and depression. No new ingredients are needed: simply an understanding of how the old ones function and permit the evolution of the newer." It seems doubtful that things like primitive subjective reactivity are only quantitatively different from complex mentation and representation, self-reflection and modulation, insight and ecstasy, despair and depression. The argument that mental faculties, in particular sentience, did not emerge but were there more or less from the start requires this inattention to qualitative differences in mental function across evolutionary time. If more attention were paid to how 
mind in a primitive species is different from mind in a complex species, the idea that all we have is gradual accretion might look less plausible.

I want to return to Reber's claim that he has now resolved the hard problem of consciousness so that we are only left with a small problem. For many of us, the hard part of the "hard problem" is why and how matter is and can be sentient, why and how matter can feel, why and how some internal states are felt. This is as opposed to the easy problems, identified by Chalmers (1996), as the questions of how biological matter might produce attention, information processing, categorizing, and the like. Chalmers supposes that these "easy problems" can be solved reductively or mechanistically but that this will still leave the hard problem - the felt aspect of some internal states (qualia) - unexplained.

Does Reber help us with this hard problem? In response to Key (2016) on whether fish feel pain, Reber declares the question moot. Every organism feels pain; pain is simply "what an organism experiences when making contact with an object or event in the environment that is causing or can cause tissue damage. It is marked as a negative experience by the organism acting to remove itself from that stimulus - a key adaptive response with clear selection advantages." What this functional definition leaves out is the feeling of pain. Reber's fish pain sounds like Lewis's (1983) Martian pain. Missing is the feeling of pain; what remains is only the adaptive response of avoidance. But surely the defining feature of pain is the fact that it feels like something. This leaves fish pain up in the air, along with Chalmers's hard problem.

Even if Reber were right that mind, and specifically sentience, is an inherent feature of all organic forms with flexible cell-walls, the question would still remain: How? And the rigid wall surrounding that mystery remains the hard problem.

\section{References}

Chalmers, D. (1996). The Conscious Mind. In Search of a Fundamental Theory. New York: Oxford University Press.

Elman, J. L., Bates, E. A., Johnson, M. H., Karmiloff-Smith, A., Parisi, D., \& Plunkett, K. (1997). Rethinking Innateness: A Connectionist Perspective on Development. Cambridge, MA: Bradford Books: The MIT Press.

Gottlieb, G. (2007). Probabilistic epigenesis. Developmental Science, 10:1, 1-11.

Key, B. (2016). Why fish do not feel pain. Animal Sentience 2016.003.

Lewis, D. (1983). Mad pain and Martian pain. In Philosophical Papers, Vol. I, 122-130. New York: Oxford.

Oyama, S. (2000). The Ontogeny of Information. Developmental Systems and Evolution. Durham, NC: Duke University Press.

Reber, A. S. (2016). Caterpillars, consciousness and the origins of mind. Animal Sentience 2016.106. 